\section{New wild diploids in Paspalum notatum Flügge (Poaceae): potential accessions for use in breeding.}

\author{
Juliana Maria Fachinetto ${ }^{1}$, Miguel Dall'Agnol², Maria \\ Teresa Schifino-Wittmann ${ }^{2}$, Carine Simioni ${ }^{2 *}$, and Mariana \\ Rockenbach Ávila ${ }^{3}$
}

\begin{abstract}
Paspalum notatum is a polymorphic species with two accepted varieties, according to the ploidy level. The ploidy level is closely related to the reproductive mode of this species. Usually, diploid cytotypes have sexual reproduction, and tetraploid cytotypes have an apomictic reproduction. Apomixis limits genetic recombination, hindering the development of new cultivars. The identification of sexual plants represents many possibilities in breeding programs. This study aimed to analyze the chromosome number in P. notatum accessions under agronomic evaluation. Ploidy level was determined in 25 accessions. Two ploidy levels were detected, resulting in 21 tetraploid and four diploid accessions. The four diploid accessions originate from Argentina and Uruguay, in a region close to the origin of Pensacola, which is a diploid sexual cultivar of P. notatum. These new diploid accessions may be useful in the development of breeding programs of Paspalum species.
\end{abstract}

Keywords: Cytogenetics, genetic breeding, ploidy level.

\section{INTRODUCTION}

Paspalum L. comprises about 350 species distributed in tropical and subtropical American natural pastures (Zuloaga and Morrone 2005). Among the species of this genus, Paspalum notatum Flügge is considered as one of the most promising forage plants in Southern Brazil due to its yield, quality, resistance, and growth (Canto-Dorow et al. 1996, Pozzobon and Valls 1997).

$P$. notatum is a polymorphic species, with two varieties, according to the ploidy level (Canto-Dorow et al. 1996). P. notatum var. saurae is diploid ( $2 \mathrm{n}=$ $2 x=20$ chromosomes), native to eastern Argentina, distributed in the provinces of Santa Fe, Corrientes, and Entre Rios (Burton 1967). Brazil has no native diploid varieties of this species, only tetraploids ( $2 n=2 x=40$ chromosomes), which occur in pastures in the Americas, from Central Mexico to Uruguay (Quarin et al. 1984).

In the genus Paspalum, polyploidy is associated with apomixis (MoraesFernandes et al. 1974, Delgado et al. 2014), which is defined as an asexual mode of reproduction by seeds (Martinez et al. 2007). This reproduction mode is an obstacle to the genetic breeding because it hinders genetic recombination and consequently cultivars protection (Huber et al. 2016). Since apomixis prevents
Crop Breeding and Applied Biotechnology 18: 432-436, 2018 Brazilian Society of Plant Breeding. Printed in Brazil http://dx.doi.org/10.1590/1984$70332018 v 18 n 4 n 63$

\footnotetext{
*Corresponding author: E-mail: carine.simioni@ufrgs.br
}

Received: 02 May 2017 Accepted: 07 June 2018

${ }^{1}$ Universidade Regional do Noroeste do Estado do Rio Grande do Sul (UNIJUI), Departamento de Ciências da Vida, Rua do Comércio, 3000, 98.700-000, ljuí, RS, Brazil

2 Universidade Federal do Rio Grande do Sul (UFRGS), Departamento de Plantas Forrageiras e Agrometeorologia, Avenida Bento Gonçalves, 7712, 91.501-970, Porto Alegre, RS, Brazil

${ }^{3}$ Universidade Federal do Pampa (UNIPAMPA), Campus Dom Pedrito, Dom Pedrito, 96.450-000, RS, Brazil 
crosses, the genetic breeding in Paspalum is limited to the identification and selection of superior tetraploid accessions, without any breeding process (Aguilera et al. 2011).

The existence of sexual genotypes is an imperative prerequisite for any breeding program of polyploid apomictic grasses (Sartor et al. 2009). In other Paspalum species, cytogenetic analyses have revealed diploid accessions (Pozzobon et al. 2008, Pozzobon et al. 2013). In P. notatum, sexual tetraploids plant were obtained by the chromosome duplication of cultivar Pensacola (Quarin et al. 2001, Weiler et al. 2015, Machado et al. 2017). However, in some cases, the mode of reproduction changes after duplication, and tetraploidized plants become apomictic (Quarin et al. 2001, Krycki et al. 2016). Quarin et al. (2001) state that the apomixis gene is present at the diploid level, but it is unexpressed in the diploid plant. The ploidy-dependence may occur at a locus that controls the apomixis using a secondary locus that involves a higher allele dosage to affect the expression of the main locus. The expression of apomixis in this duplicated plant is possibly a gene-dosage effect.

The search of diploids in germplasm banks associated with morphologic and molecular analyses could distinguish new diploid accessions of $P$. notatum Pensacola. Moreover, the analysis of their agronomic performance could indicate their use in breeding programs of this species. Based on these considerations, this study aimed to determine the ploidy level in a collection of $P$. notatum accessions subject to agronomic and morphologic evaluation.

\section{MATERIAL AND METHODS}

A cytogenetic study was carried out on $25 P$. notatum accessions. These materials belong to the Germplasm Bank of the United States Department of Agriculture (USDA) and were collected from the years of 1950 to 1970 in Southern Brazil, Argentina, Uruguay, and Paraguay (Fig. 1). For this study, plants were obtained from an experiment for the agronomic evaluation conducted by Fachinetto et al. (2012). Ploidy level was determined from the gametic chromosome number and pollen mother cells (PMC) analysis. During the summer of 2010, young inflorescences of two individuals randomly chosen from each accession were collected and fixed in Carnoy 3:1 (ethanol: acetic acid) for 24 hours, at room temperature, and stored in ethanol $70 \%$ under refrigeration (Pereira et al. 2014, Moreira et al. 2017). Slides were prepared by isolating the anthers, squashing, and staining with $1 \%$ propionic carmine (Pagliarini et al. 2002, Simioni and Vale 2009). Cells were analyzed in an optical microscope, totaling ten cells per individual. Gametic chromosome numbers were determined in diakinesis/ metaphase I and anaphase I when the chromosomes showed visible and adequate spread. The ploidy level was determined considering $\mathrm{x}=10$ chromosomes, described as the basic number for the species (Dahmer et al. 2008).

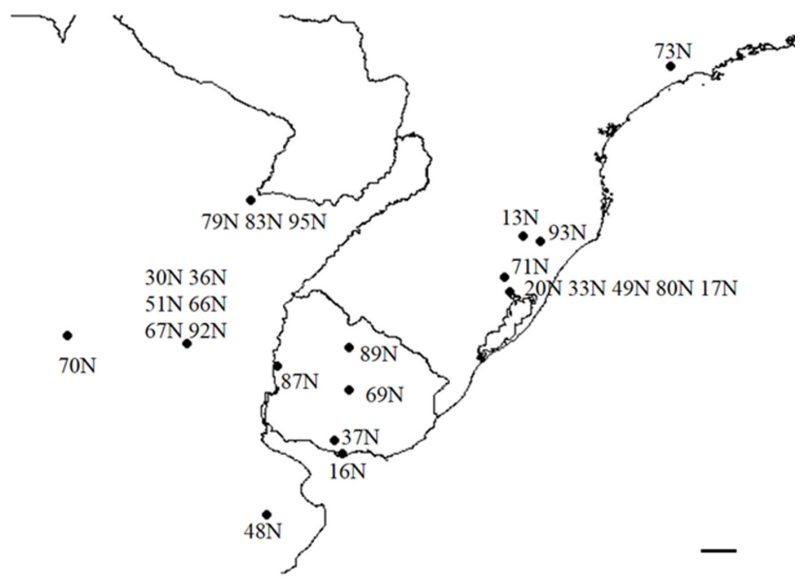

Figure 1. Location of $P$. notatum accessions. Scale: $100 \mathrm{~km}$.

Table 1. Ploidy level of $P$. notatum accessions

\begin{tabular}{|c|c|c|}
\hline Accessions & Identification & Ploidy \\
\hline $13 N$ & PI404473 & $4 x$ \\
\hline $16 \mathrm{~N}$ & PI276251 & $4 x$ \\
\hline $17 \mathrm{~N}$ & PI214118 & $4 x$ \\
\hline $20 N$ & PI508826 & $4 x$ \\
\hline $30 N$ & PI508833 & $4 x$ \\
\hline $33 N$ & PI310169 & $4 x$ \\
\hline $36 N$ & PI508834 & $4 x$ \\
\hline $37 \mathrm{~N}$ & PI404861 & $4 x$ \\
\hline $48 N$ & PI508838 & $4 x$ \\
\hline $49 N$ & PI310168 & $4 x$ \\
\hline $51 \mathrm{~N}$ & PI337566 & $4 x$ \\
\hline $66 \mathrm{~N}$ & PI508832 & $2 x$ \\
\hline $67 N$ & PI337573 & $2 x$ \\
\hline $69 N$ & PI404866 & $4 x$ \\
\hline $70 N$ & PI508828 & $4 x$ \\
\hline $71 N$ & PI310145 & $4 x$ \\
\hline $73 N$ & PI241878 & $4 x$ \\
\hline $79 N$ & PI508840 & $4 x$ \\
\hline $80 N$ & PI310170 & $4 x$ \\
\hline $83 N$ & PI508827 & $4 x$ \\
\hline $87 N$ & PI404863 & $2 x$ \\
\hline $89 N$ & PI404865 & $4 x$ \\
\hline $92 \mathrm{~N}$ & PI508831 & $2 x$ \\
\hline $93 N$ & PI404476 & $4 x$ \\
\hline $95 N$ & PI424652 & $4 x$ \\
\hline
\end{tabular}




\section{RESULTS AND DISCUSSION}

The chromosome number of the $25 P$. notatum accessions was determined. In this study, 21 accessions were tetraploid $(2 n=4 x=40$ chromosomes) and four accessions were diploid $(2 n=2 x=20$ chromosomes) (Table 1, Figure 2). These data corroborated the findings of other authors, indicating that tetraploids are more common than diploids in Paspalum. Adamowski et al (2005) analyzed 36 Paspalum accessions, revealing one diploid $(2 n=2 x=20), 34$ tetraploids $(2 n=4 x$ $=40)$, and one hexaploid $(2 n=6 x=60)$. In a study with $P$. lepton, all the 53 accessions analyzed were tetraploid (Reis et al. 2008). In P. notatum, Pozzobon and Valls (1997) demonstrated that $90 \%$ of the accessions were tetraploid and $10 \%$ were diploid. Similar results were obtained in a study with 92 accessions, of which 83 were tetraploid, one was hexaploid $(2 n=6 x=60)$, and eight were diploid, of which seven corresponded to Pensacola, used as control, and one was considered as an escape of Pensacola (Dahmer et al. 2008).

In this study, the diploid accessions were not considered as an escape of Pensacola due to their origin. Accessions $66 \mathrm{~N}, 67 \mathrm{~N}$, and $92 \mathrm{~N}$ were collected in Santa Fe, Argentina, while $87 \mathrm{~N}$ was collected in Paysandú, Uruguay (Figure 1, Table 1). These four accessions were considered as wild diploids since they were collected in the origin region of Pensacola (Burton 1967).

These accessions are part of a larger $P$. notatum collection and were evaluated for agronomic, morphological, and molecular aspects. Dry matter yield was higher in three diploid accessions (66N, 67N and 92N); however, these accessions did not differ from $87 \mathrm{~N}$ when compared with Pensacola. $66 \mathrm{~N}$ and $67 \mathrm{~N}$ produced about four times more, and $92 \mathrm{~N}$ produced about seven times more than Pensacola. Furthermore, these accessions showed superior persistence to winter conditions than Pensacola (Fachinetto et al. 2012). Moreover, morphological analyses indicated that the four diploid accessions grouped separately from each other and Pensacola (Fachinetto et al. 2017).

This separation into different morphological and molecular groups may be due to the higher variability since these accessions are probably of sexual reproduction. P. notatum var. saurae has narrower leaves, small spikelets, and more racemes per inflorescence (Quarin et al. 1984, Canto-Dorow et al. 1996), being classified together with plants from sexual reproduction. So far, all the diploid plants of this species (wild or cultivated) are typically sexual (Espinoza and Quarin 1997, Daurelio et al. 2004, Pozzobon et al. 2008). Delgado et al. (2014) stated that genetic determinants of apomixis found in diploids are not sufficient for a considerable expression of the trait, as found in $P$. rufum, and that the gene expression of this trait is related to other factors.

Apomixis is a type of asexual reproduction in which seeds formation occurs without fertilization. The resulting individuals are genetically identical to the plant that originated them. Asexual reproduction allows the genotypes to be fixed, and the desired traits to be maintained. Due to the absence of recombination, this phenomenon maintains the presence of gene blocks and linked genes, allowing the continuous exploration of heterosis, besides eliminating the need for plant isolation during seed production. However, plants that reproduce exclusively by apomixis hinder breeding processes for preventing genetic recombination between individuals, making them highly dependent on mutations to evidence genetic variability (Carvalho et al. 2008). These diploids, which probably present sexual reproduction, could be used for crossing between each other or even with Pensacola, without chromosome doubling. These findings would ensure
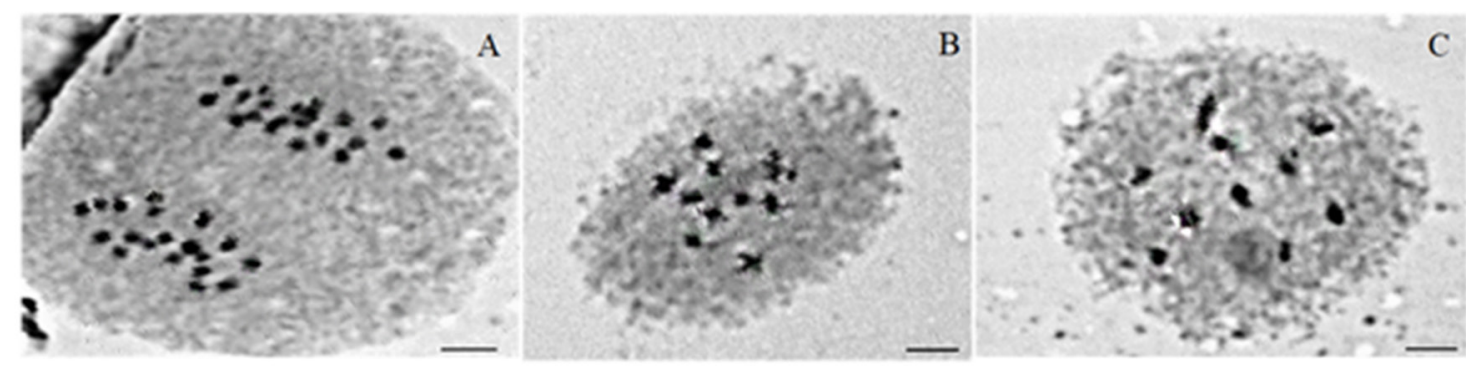

Figure 2. Pollen mother cells (PMC) in P. notatum. A - Accession $36 \mathrm{~N}$, anaphase $\mathrm{I}, \mathrm{n}=2 \mathrm{x}=20$ chromosomes in each pole. $\mathrm{B}-$ Accession $66 \mathrm{~N}$, diakinesis, $\mathrm{n}=\mathrm{x}=10$ bivalent chromosomes. $\mathrm{C}-$ Accession $92 \mathrm{~N}$, diakinesis, $\mathrm{n}=\mathrm{x}=10$ bivalent chromosomes. Scale: $10 \mu \mathrm{m}$. 
New wild diploids in Paspalum notatum Flügge (Poaceae): potential accessions for use in breeding.

sexual accessions for crossing since chromosome doubling can lead to apomixis (Quarin et al. 2001, Krycki et al. 2016).

Sexual plants with superior traits could be used in new recombinations within the breeding program, in the formation of new individuals, maximizing the benefits of hybrid vigor (Burton et al. 1973, Jank et al. 2011, Lopes et al. 2018).

After the crossing between the diploids and the obtainment of plants with favorable traits and heterosis, chromosome doubling could lead to apomictic tetraploid plants to be used to keep desired traits. The findings of this work may contribute to the Paspalum species, especially P. notatum, conferring new possibilities of crossing and insertion of genetic variability in breeding programs.

\section{ACKNOWLEDGMENTS}

The authors thank Capes and CNPq, for the financial support, and USDA, for granting the seeds.

\section{REFERENCES}

Adamowski EV, Pagliarini MS, Bonato ABM, Batista LAR and Valls JFM (2005) Chromosome numbers and meiotic behavior of some Paspalum accessions. Genetics and Molecular Biology 28: 773-780.

Aguilera PM, Galdeano F, Espinoza F and Quarín CL (2011) Interspecific tetraploid hybrids between two forage grass species: sexual Paspalum plicatulum and apomictic P. guenoarum. Crop Science 51: 1544-1550.

Burton GW (1967) A search for the origin of Pensacola bahiagrass. Economic Botanic 21: 319-382.

Burton GW, Millot JC and Monson WG (1973) Breeding procedures for Panicum maximum Jacq. suggested by plant variability and mode of reproduction. Crop Science 13: 717-720.

Canto-Dorow TS, Longui-Wagner HM and Valls JFM (1996) Revisão taxonômica das espécies de Paspalum L. grupo Notata (Poaceae Paniceae) do Rio Grande do Sul, Brasil. Iheringia 47: 4-44.

Carvalho FIF, Lorencetti C, Marchioro VS and Silva AS (2008) Condução de populações no melhoramento genético de plantas. Editora Universitária, Pelotas, 288p.

Dahmer N, Schifino-Wittmann MT, Dall'Agnol M and Castro B (2008) Cytogenetic data for Paspalum notatum Flügge accessions. Scientia Agrícola 65: 381-388.

Daurelio LD, Espinoza F, Quarin CL and Pessino SC (2004) Genetic diversity in sexual diploid and apomictic tetraploid populations of Paspalum notatum situated in sympatry or allopatry. Plant Systematics and Evolution 244: 189-199.

Delgado L, Galdeano F, Sartor ME, Quarin CL, Espinoza F and Ortiz JPA (2014) Analysis of variation for apomictic reproduction in diploid Paspalum rufum. Annals of Botany 113: 1211-1218.

Espinoza F and Quarin CL (1997) Cytoembryology of Paspalum chaseanum and sexual diploid biotypes of two apomictic Paspalum species. Australian Journal of Botany 45: 871-877.

Fachinetto JM, Dall'Agnol M, Souza CHL, Weiler RL and Simioni C (2017) Genetic diversity of a Paspalum notatum Flügge germplasm collection. Revista Brasileira de Zootecnia 46: 714-721.

Fachinetto JM, Schneider R, Hubber KGC and Dall'Agnol M (2012) Avaliação agronômica e análise da persistência em uma coleção de acessos de Paspalum notatum Flügge (Poaceae). Agrária 7: 189-195.

Huber KGC, Dall'Agnol M, Motta EAM, Pereira EA, Ávila MR, Perera MZ and Santos TN (2016) Variabilidade agronômica e seleção de progênies F1 de Paspalum. Agrária 11: 374-380.

Jank L, Valle CB and Resende RMS (2011) Breeding tropical forages. Crop Breeding and Applied Biotechnology 11: 27-34.

Krycki KC, Simioni C and Dall'Agnol M (2016) Cytoembryological evaluation, meiotic behavior and pollen viability of Paspalum notatum tetraploidized plants. Crop Breeding and Applied Biotechnology 16: 282-288.

Lopes RR, Franke LB, Souza CHL de, Bertoncelli P, Graminho LA and Pereira EA (2018) Genetic parameters and predicted gains with selection of interspecific hybrids of Paspalum for seed production. Crop Breeding and Applied Biotechnology 18: 284-291.

Machado JM, Dall'Agnol M, Motta EAM, Pereira EA, Simioni C, Weiler RL, Zuñeda MP and Ferreira PB (2017) Agronomic evaluation of Paspalum notatum Flügge under the influence of photoperiod. Revista Brasileira de Zootecnia 46: 8-12.

Martínez EJ, Acunã CA, Hojsdaard DH, Tcach MA and Quarin CL (2007) Segregation for sexual seed production in Paspalum as directed by male gametes of apomictic triploid plants. Annals of Botany 100: 1239-1247.

Moreira, NF, Pereira TNS and Martins KC (2017) Meiotic analysis of interspecific hybrids between Capsicum frutescens and Capsicum chinense. Crop Breeding and Applied Biotechnology 17: 159-163.

Moraes-Fernandes MIB, Barreto IL, Salzano FM and Sacchet AMOF (1974) Cytological and evolutionary relationships in brazilian forms of Paspalum (Gramineae). Caryologia 27: 455-464.

Pagliarini MS, Defani MA, Meirelles WF and Pereira JE (2002) Recurrence of multiple meiotic abnormalities in maize genotypes from the same origin and their influence on productivity. Crop Breeding and Applied Biotechnology 2: 355-360.

Pereira RC, Ferreira MTM, Davide LC, Pasqual M, Mittelmann A and Techio VH (2014) Chromosome duplication in Lolium multiflorum Lam. Crop Breeding and Applied Biotechnology 14: 251-255. 


\section{JM Fachinetto et al.}

Pozzobon MT and Valls JFM (1997) Chromosome number in germplasm accessions of Paspalum notatum (Gramineae). Brazilian Journal of Genetics 20: 29-34.

Pozzobon MT, Machado ACC, Vaio M, Valls JFM, Peñaloza APS, Santos S, Côrtes AL and Rua GH (2008) Cytogenetic analyses in Paspalum L. reveal new diploid species and accessions. Ciência Rural 38: 1292-1299.

Pozzobon MT, Paganela MB, Santos S and Valls JFM (2013) Cytological and reproductive aspects in the Caespitosa group of Paspalum. Ciência Rural 43: 2004-2010.

Quarin CL, Espinoza F, Martinez EJ, Pessino SC and Bovo OA (2001) A rise of ploidy level induces the expression of apomixis in Paspalum notatum. Sexual Plant Reproduction 13: 243-249.

Quarin CL, Burson BL and Burton GW (1984) Cytology of intra and interspecific hybrids between two cytotypes of Paspalum notatum and $P$. cromyorrhizon. Botanical Gazette 145: 420-426.
Reis CAO, Schifino-Wittmann MT and Dall'Agnol M (2008) Chromosome numbers, meiotic behavior and pollen fertility in a collection of Paspalum nicorae Parodi accessions. Crop Breeding and Applied Biotechnology 8: 212-218.

Sartor ME, Quarin CL and Espinoza F (2009) Mode of reproduction of colchicine-induced Paspalum plicatulum tetraploids. Crop Science 49: $1270-1276$.

Simioni C and Valle CB (2009) Chromosome duplication in Brachiaria (A. Rich.) Stapf allows intraspecific crosses. Crop Breeding and Applied Biotecnology 9: 328-334.

Weiler RL, Krycki KC, Guerra D, Simioni C and Dall'Agnol M (2015) Chromosome doubling in Paspalum notatum var. saure (cultivar Pensacola). Crop Breeding and Applied Biotechnology 15: 106-111.

Zuloaga FO and Morrone O (2005) Revisión de las especies de Paspalum para América del Sur austral (Argentina, Bolivia, sur del Brasil, Chile, Paraguay y Uruguay). Monographs in Systematic Botany 102: 1-297. 